\title{
IMPROVEMENT VISCOSITY INDEX OF LUBRICATING ENGINE OIL USING LOW MOLECULAR WEIGHT COMPOUNDS
}

\author{
Shinwar Ahmed Idrees ${ }^{\mathrm{a}}{ }^{*}$, Lawand Luqman Mustafa ${ }^{\mathrm{b}}$, Sabah Sardar Saleem ${ }^{\mathrm{c}}$ \\ a Faculty of Science, University of Zakho, Kurdistan Region, Iraq - (shinwar.idrees@uoz.edu.krd.) \\ ${ }^{\mathrm{b}}$ Faculty of Science, Duhok polytechnic university, Kurdistan Region, Iraq - (Lawand.luqman@dpu.edu.krd.) \\ ${ }^{\mathrm{c}}$ Faculty of Science, Duhok polytechnic university, Kurdistan Region, Iraq - (sabahsardar2022@gmail.com)
}

Received: Nov. 2018 / Accepted: Dec., 2018 / Published: Mar., 2019

https://doi.org/10.25271/sjuoz.2019.7.1.572

\begin{abstract}
:
the effect of polarity of solvent on the viscosity and viscosity index of lubricating engine oil has been studied using ethanol as an example of polar solvent and toluene as an example of non-polar solvent at different solvent ratios and ambient temperature and additionally other experiments have been done at five different temperatures including $100 \mathrm{oC}$. So that, the activation energy of viscous flow (Ea) was calculated, and for this purpose Arrhenius viscosity-temperature dependence has been applied and the results were $42.128,29.256$ and $35.417 \mathrm{KJ} / \mathrm{mole}$ for lubricating engine oil mixed with ethanol, toluene and no additives in turn. It additionally shows that adding polar solvent to lubrication engine oil viscosity increases this may be due to the fact of strong inter molecular forces that found in polar molecules such as hydrogen bonding in ethanol makes the solution forces stronger as a result higher viscosity. However, adding non-polar solvent decreases viscosity because of small size of toluene and both paraffinic lubricating oil and toluene have same London dispersion inter molecular forces. Last not least, the result shows that engine oil mixed with non-polar molecule gives more temperature stability than that of polar molecule giving viscosity index (VI) 366 and 580 respectively.
\end{abstract}

KEYWORDS: Engine Oil, Kinematic Viscosity, Viscosity Index.

\section{INTRODUCTION}

Viscosity is considered that it is affected by temperature of the system. In other word, it is a thermally activated process. For the liquid to follow the movement of the molecule have to overcome the energy barriers that created by inter molecular forces such as hydrogen bonding, dipole-dipole interactions .....etc, and by the resistance of the surrounding building units (Avramov, 2007; D. J. Cnonrn, J . T. Wer. Rzbnr-N n D. A. Keuppueu 1983; R. EADA, H. ANZAWA. 1965).

Viscosity is assumed a very important parameter of physical properties of a liquid, and due to it is importance. It has to be taken into account in many engineering design and scientific calculation because viscosity determines the hydrodynamic properties of fluid such as flow rate through pipe lines, pressure drop in industrial processes....etc (E. I. Epelle, A. J. Otaru, Y. O. Zubair, J. A. Okolie. 2017).

As mentioned above viscosity is greatly affected by inter molecular forces that can be found among molecule, therefor addition of polar and non-polar solvent changes the liquid polarity as well as viscosity (R. B. H. Kacema, N. O. Alzamela,N. Ouerfelli. 2017). Many chemicals including solvents are mixed with engine oil in order to modify viscosity index number of lubricating engine oil such chemicals improves the viscosity/ temperature characteristic of lubricating oil. Molecular size of modifier plays an important role in changing viscosity of a solution (Mark W. Badger, Harold H. Schobert. 2005). In this research we studied the effect of low molecular weight chemicals and also we have studied the effect of polarity and temperature dependence of viscosity for lubricating engine oil.

The majority of viscosity improver gives higher viscosity at normal ambient temperature when mixed with engine oil, while other compound decreases viscosity. However, it is not necessary for such additive to be viscosity-temperature stable (Mead, Theodore C. and Odell, Norman R. 1974; Girotti, Pier Leone, Tesei, Renato and Floris, Telemaco. 1974). To investigate the effect of temperature on the stability of engine oil viscosity index (VI) has been measured applying ASTM D2270 and ISO 2909 method (E. I. Epelle, A. J. Otaru, Y. O. Zubair, J. A. Okolie. 2017, Cragg, J . C. and Evans, E. A.1943).

\section{EXPERIMENTAL PART}

The lubricating engine oil was purchased type Multi Flo SAE $5 \mathrm{~W}-30$, and used as received. Toluene and ethanol were purchased from ScharIau, analytical grade, ACS, Reag, Ph Eur and utilized without any change or dilution. Viscometers glass type CFOV-CANNON-FENSKE RESERVE folw viscometer mod.22-0059 has been purchased as shown in fig.1. Circulating water bath has been used for controlling temperature type petrotest. The reading was recorded in different temperature $(30,35,40$ and $45 \mathrm{oC})$ to study the effect of temperature and to determine the Arrhenius energy of follow activation. In order to investigate the influence of polarity and temperature on viscosity two milliliter of polar or non-polar solvent is mixed with eighteen milliliter of lubricating engine oil as appeared in table 3,4, and 5. In addition to that different ratios of ethanol and toluene was added to lubricating engine oil at ambient temperature circa $22 \mathrm{oC}$ to determine the effect of polar and non-polar solvent as in table land 2.

For the study the effect of temperature on viscosity of solution, $2 / 18 \mathrm{~mL}$ solvent to lubricating engine oil ratio was taken and put in viscometer then viscometer was placed in circulating water bath in order to keep temperature of solution constant. For each solvent procedure has been applied separately four times at different temperatures.

To study the effect of solvent polarity, different ratios of solvent/ lubricating engine oil was mixed as shown in table 1 and 2 , and then placed in viscometer to record the viscosity of the solution. All readings were taken at room temperature, the time interval between two tests was only preparation time. To calculate viscosity index, viscosity at $100 \mathrm{oC}$ and $40 \mathrm{oC}$ were measured using ASTM D2270 method for each sample, as shown in table 6 . 
Table 1. Kinematic Viscosity Measurement After the Addition of Polar Solvent Ethanol:

\begin{tabular}{|l|l|l|}
\hline $\begin{array}{l}\text { Volume of } \\
\text { oil }\end{array}$ & $\begin{array}{l}\text { Ethanol } \\
\text { volume }\end{array}$ & $\begin{array}{l}\text { Kinematic } \\
\text { viscosity }\end{array}$ \\
\hline $19 \mathrm{ml}$ & $1 \mathrm{ml}$ & $84 \mathrm{cst}$ \\
\hline $18 \mathrm{ml}$ & $2 \mathrm{ml}$ & $88.5 \mathrm{cst}$ \\
\hline $17 \mathrm{ml}$ & $3 \mathrm{ml}$ & $104.5 \mathrm{cst}$ \\
\hline
\end{tabular}

Table 2: kinematic viscosity measurement after the addition of non-polar solvent Toluene

\begin{tabular}{|l|l|l|}
\hline $\begin{array}{l}\text { Volume of } \\
\text { oil }\end{array}$ & $\begin{array}{l}\text { Toluene } \\
\text { volume }\end{array}$ & $\begin{array}{l}\text { Kinematic } \\
\text { viscosity }\end{array}$ \\
\hline $19 \mathrm{ml}$ & $1 \mathrm{ml}$ & $77.5 \mathrm{cst}$ \\
\hline $18 \mathrm{ml}$ & $2 \mathrm{ml}$ & $34 \mathrm{cst}$ \\
\hline $17 \mathrm{ml}$ & $3 \mathrm{ml}$ & $25 \mathrm{cst}$ \\
\hline
\end{tabular}

Table 3: kinematic viscosity of only lubrication engine oil at different temperature.

\begin{tabular}{|l|l|}
\hline Temperature & $\begin{array}{l}\text { Kinematic } \\
\text { viscosity }\end{array}$ \\
\hline $30{ }^{\circ} \mathrm{C}$ & $104.75 \mathrm{cSt}$ \\
\hline $35^{\circ} \mathrm{C}$ & $85.5 \mathrm{cSt}$ \\
\hline $40^{\circ} \mathrm{C}$ & $69.25 \mathrm{cSt}$ \\
\hline $45^{\circ} \mathrm{C}$ & $53.75 \mathrm{cSt}$ \\
\hline
\end{tabular}

Table 4: kinematic viscosity of $18 \mathrm{~mL}$ of lubrication engine oil $+2 \mathrm{~mL}$ of ethanol at different temperature.

\begin{tabular}{|l|l|}
\hline Temperature & $\begin{array}{l}\text { Kinematic } \\
\text { viscosity }\end{array}$ \\
\hline $30^{\circ} \mathrm{C}$ & $85.625 \mathrm{cSt}$ \\
\hline $35^{\circ} \mathrm{C}$ & $63 \mathrm{cSt}$ \\
\hline $40^{\circ} \mathrm{C}$ & $51.75 \mathrm{cSt}$ \\
\hline $45^{\circ} \mathrm{C}$ & $38.05 \mathrm{cSt}$ \\
\hline
\end{tabular}

Table 5: kinematic viscosity of $18 \mathrm{~mL}$ of lubrication engine oil $+2 \mathrm{~mL}$ of toluene at different temperature.

\begin{tabular}{|l|l|}
\hline Temperature & $\begin{array}{l}\text { Kinematic } \\
\text { viscosity }\end{array}$ \\
\hline $30{ }^{\circ} \mathrm{C}$ & $38.45 \mathrm{cSt}$ \\
\hline $35^{\circ} \mathrm{C}$ & $31.15 \mathrm{cSt}$ \\
\hline $40^{\circ} \mathrm{C}$ & $26.1 \mathrm{cSt}$ \\
\hline $45^{\circ} \mathrm{C}$ & $22.2 \mathrm{cSt}$ \\
\hline
\end{tabular}

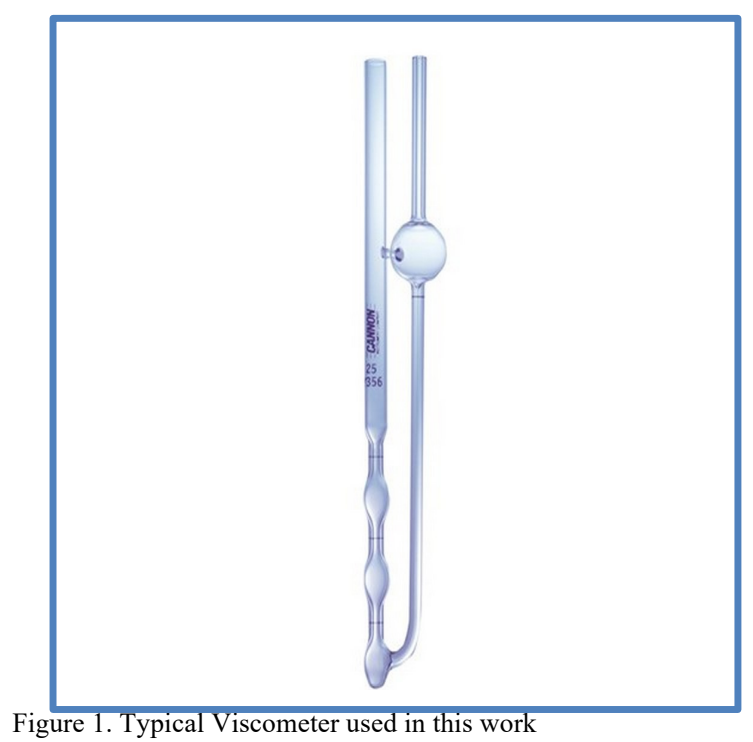

\section{RESULT AND DISCUSSION}

\subsection{Viscosity index}

Viscosity index was measured using ASTM D2270 and ISO 2909 method (E. I. Epelle, A. J. Otaru, Y. O. Zubair, J. A. Okolie. 2017, Cragg, J . C. and Evans, E. A. 1943). Viscosity index calculations have been done for two low molecular weight solvents with a ratio of $80 \%$ of lubricating engine oil, polar (ethanol) and the other was non polar (toluene) as shown in table 6.
Table 6: viscosity index.

\begin{tabular}{|l|c|c|}
\hline Compound & $\begin{array}{l}\text { Kinematic } \\
\text { viscosity at } 100{ }^{\circ} \mathrm{C}\end{array}$ & $\begin{array}{l}\text { Viscosity index } \\
\text { (VI) }\end{array}$ \\
\hline Without any Additive & $24.64 \mathrm{cSt}$ & 375 \\
\hline Mixed with Ethanol & $18.06 \mathrm{cSt}$ & 366 \\
\hline Mixed with toluene & $15.09 \mathrm{cSt}$ & 580 \\
\hline
\end{tabular}

The result of (VI) shows that non-polar molecule of toluene mixed with $80 \%$ engine oil is more stable than that of polar molecule of ethanol 366 and 580 respectively, as shown in table 6.

\subsection{Effect of inter molecular forces}

Effect of solvent polarity on the viscosity of lubricating engine oil has been studied using two solvents with a ration $2 \mathrm{~mL}$ of each mixed $18 \mathrm{~mL}$ of lubricating engine oil. One of the utilized solvent was polar (ethanol) and the other was non polar (toluene).

The results shows that polar solvent increases the lubricating engine oil viscosity, while non-polar solvents decreases viscosity. This may be due to fact that non-polar molecule contains only one attraction force between molecules which is vander-waals force (London dispersion force) only (R. Thomas Myers, Salvatore Tocci, Keith B. Oldham. 2006) and also the distance between tow molecules determine the strength of potential energy that exist between them as both lubricating oil engine and toluene have the same weak force. On the other hand, for a liquid consisting of a polar molecules in addition to the inter molecular potential energy, molecules contains energy caused by electrical dipole momentum of the polar molecule, and the value of the dipole moments of that polar molecule determines the strength of attraction force between molecules (H. Guangze, F. ZengKe, C. MingDong.2010; Jos C. M. Kistemaker, Anouk S. Lubbe, Erik A. Bloemsma, and Ben L. 2016; M.A. Haidekker, T.P. Brady, D. Lichlyter, E.A. Theodorakis. 2005). As a rule, the viscosity of solution increases as the additive polarity increase because of stronger dipole-dipole interaction (E. I. Epelle, A. J. Otaru, Y. O. Zubair, J. A. Okolie.2017). as shown in table $3,4,5$ at different temperature and table 1,2 and fig. 2 shows different solvent ratio and ambient temperature circa $22 \mathrm{oC}$.

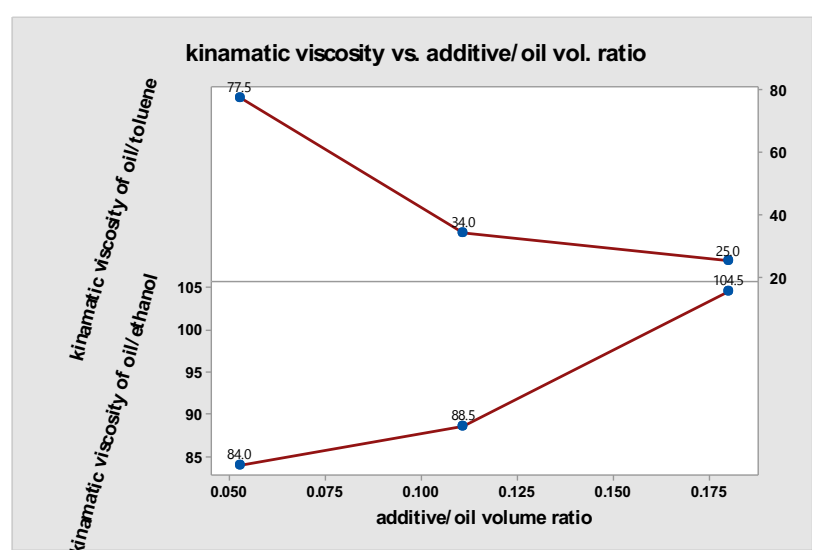

Figure 2. Kinematic viscosity of lubricating engine oil mixed with toluene and ethanol as a function of solvent/oil ratio.

\subsection{Effect of temperature}

Arrhenius viscosity-temperature dependence equation has been used to calculate activation energy of viscous flow. The logarithm of viscosity $(\operatorname{lnf})$ versus the reciprocal of absolute temperature $(1 / T)$ gives the slope equal to energy of activation by gas constant (Ea/R) (D. J. Cnonrn, J . T. Wer. Rzbnr-N n D. A. Keuppueu.1983; R. B. H. Kacema, N. O. Alzamela,N. Ouerfelli.2017; A. Messaâdi, N. Dhouibi, H. Hamda, F. Bin M.Belgacem,Y. H. Adbelkader, N. Ouerfelli, and A. H. Hamzaoui.( 2015). 


$$
\operatorname{Ln}(\varsubsetneqq)=\operatorname{Ln}(A)+\frac{E a}{R} * \frac{1}{T}
$$

It is shown from fig. 4,5 and 6 as the temperature increase the viscosity of solution was decreased (D. J. Cnonrn, J . T. Wer. Rzbnr-N n D. A. Keuppueu.1983; EADA, H. ANZAWA. 1965; V. Kumbár, J. Votava.2014). The activation energy of viscous flow was measured using Arrhenius plot. The results were $42.128,29.256$ and $35.417 \mathrm{~kJ} /$ mole for lubricating engine oil mixed with ethanol, toluene and no additives respectively. It additionally illustrate that mixing lubricating engine oil with polar compound like ethanol activation energy of viscous flow increases, this may be because of stronger inter molecular forces that exist between polar molecules. On the other hand, when oil mixed with non-polar compounds such as toluene activation energy of viscous flow was decreased, this perhaps due to small molecular size of toluene if it compared with paraffinic like molecule of oil and both toluene and lubricating engine oil has nearly same polarity and molecular forces as shown in table 7 and figure 3 .

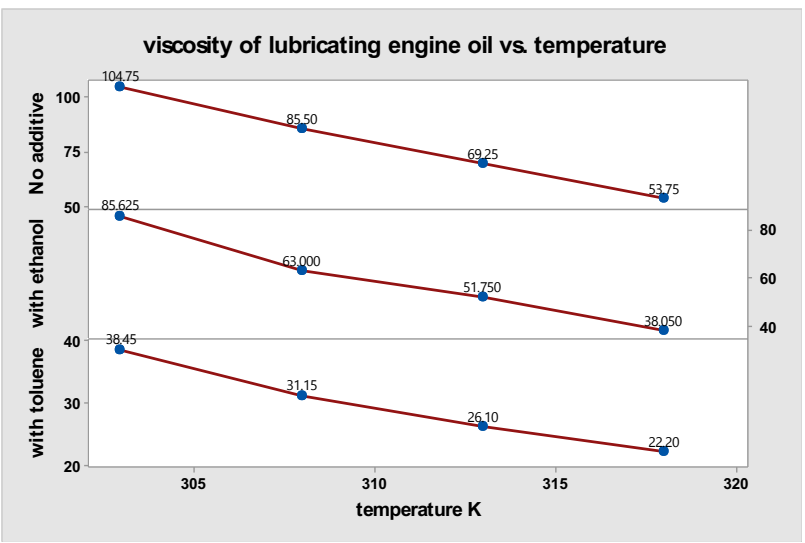

Figure 3. Viscosity of lubricating engine oil without additive, with ethanol $(2: 18 \mathrm{~mL})$ and with toluene $(2: 18 \mathrm{~mL})$ as a function of temperature.

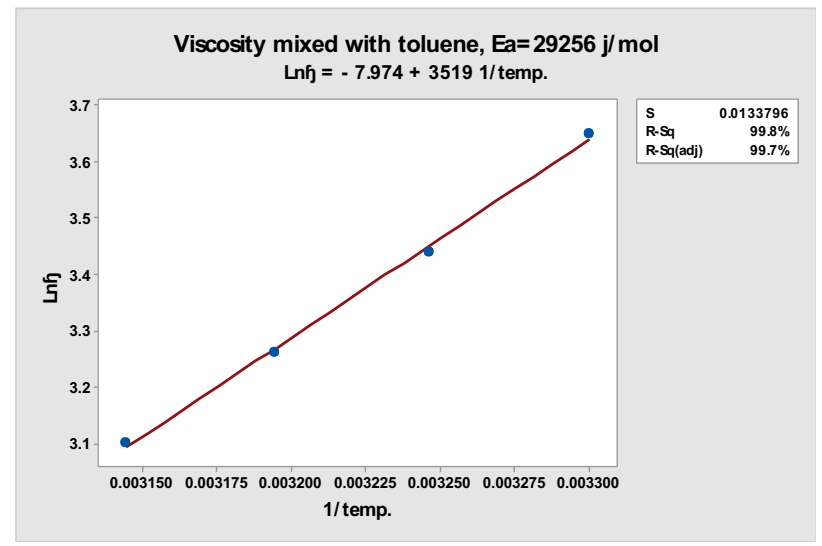

Figure 4. Arrhenius viscosity-temperature plot when $18 \mathrm{~mL}$ of lubricating engine oil mixed with $2 \mathrm{~mL}$ toluene.

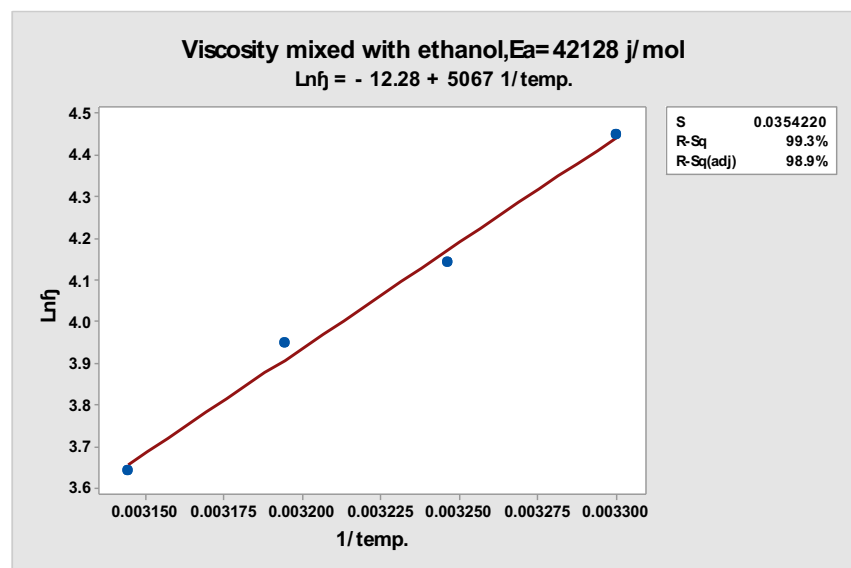

Figure 5. Arrhenius viscosity-temperature plot when $18 \mathrm{~mL}$ of lubricating engine oil mixed with $2 \mathrm{~mL}$ ethanol.

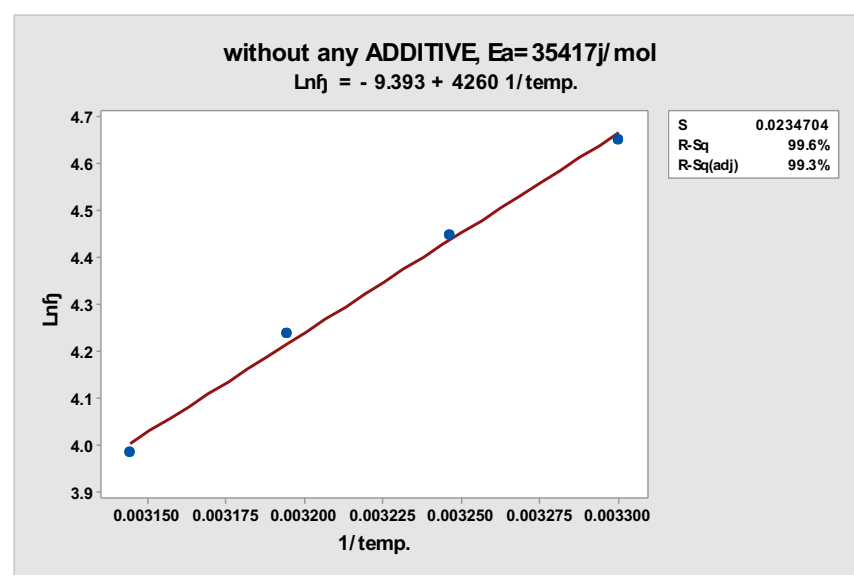

Figure 6. Arrhenius viscosity-temperature plot of lubricating oil engine without any additives.

TABLE 7. activation energy of viscous flow with and with out additives.

\begin{tabular}{|l|l|l|l|}
\hline & $\begin{array}{c}\text { 2mL ethanol } \\
\text { mixed with } \\
18 \mathrm{~mL} \\
\text { lubricating } \\
\text { engine oil }\end{array}$ & $\begin{array}{c}\text { 2mL toluene } \\
\text { mixed with } \\
18 \mathrm{~mL}\end{array}$ & No additives \\
& $\begin{array}{c}\text { lubricating } \\
\text { engine oil }\end{array}$ & \\
\hline $\mathrm{Ea} \mathrm{J} / \mathrm{mole}$ & 42128 & 29256 & 35417 \\
\hline $\mathrm{R}^{2} \%$ & 99.3 & 99.8 & 99.6 \\
\hline
\end{tabular}

\section{CONCLUSION}

All in all, the viscosity of lubricating engine oil has been examined under the influence of polar and non-polar solvent. Arrhenius plot for viscosity-temperature dependence was applied to measure activation energy of viscous flow for lubricating engine oil mixed with polar, non-polar solvent and without additives. The result had shown that as the ratio of polar solvent increase directly effect on the viscosity, but this is untrue with non-polar solvent which is adversely influence on the viscosity of lubricating engine oil. It additionally has been found polar solvent increases activation energy of viscous flow and vice versa with non-polar solvent. The results investigate that engine oil mixed with non-polar toluene gives more temperature stability than that of polar ethanol giving viscosity index (VI) 366 and 580 in turn.

\section{SUGGESTION FOR FUTURE WORK}

In future, new research will be performed utilizing lubricating oil without any additives and maximum range of VI that can be 
reached will be determined. In addition multi types of lubricants will be used.

\section{REFERENCES}

Avramov, I. (February 2007). Viscosity activation energy. Phys. Chem. Glasses: Eur. J. Glass Sci. Technol. B, 48 (1), 61-63.

AymenMessaâdi, N. D. (2015). A New Equation Relating the Viscosity Arrhenius Temperature and the Activation Energy for Some Newtonian Classical Solvents. Journal of Chemistry, 1-12.

Cragg, J. ... \& Evans, E. A. (1943). VISCOSITY 'MEASUREMENT AND VISCOSITY INDEX. NEW YOURK: C. C. Wakefield cCCo., Ltd

E. I. Epelle, A. J. (2017). Improving the Viscosity Index of Used Lubricating Oil by Solvent Extraction. International Research Journal of Engineering and Technology (IRJET), pp. 1581-1585

Epelle, E. I., Otaru, A. J., Zubair, Y. O., \& Okolie, J. A. (2017) Improving the Viscosity Index of Used Lubricating Oil by Solvent extraction. $04 p p(1581-1585)(12)$.

Girotti, P. L., Tesei, R., \& Floris, T. (1974, 3 12). Patent No. 450,317. Italy .
HAN GuangZe, F. Z. (2010). Modified Eyring viscosity equation and calculation of activation energy based on the liquid quasilattice model. SCIENCE CHINA, Vol.53 pp:1853-1851.

Jos C. M. Kistemaker, A. S. (2016). On the Role of Viscosity in the Eyring Equation. ChemPhysChem, vol. 17,pp: 1819-1822.

M.A. Haidekker, T. B. (2005). Effects of solvent polarity and solvent viscosity on the fluorescent properties of molecular rotors and related probes. Bioorganic Chemistry, 33 pp:415-425( 33 415-425), vol.33,pp: 415-425.

Mark W. Badger, H. H. (2005). Viscosity Reduction in Extra Heavy Crude Oils. The Pennsylvania State University, 461-466.

Mead, T. C., \& Odell, N. R. (1974, 7 20). Patent No. 242,143. United States.

R. B. H. Kacema, N. O. (2017, Vol. 91, No. 9). Sensitivity of Viscosity Arrhenius Parameters to Polarity of Liquids. Russian Journal of Physical Chemistry A, pp. 1654-1659.

R. Thomas Myers, S. T. (2006). HOLT chemistry. In S. T. R. Thomas Myers, state of matter and inter molecular forces ( $\mathrm{pp}$ pp:376-414). Holt, Rinehart and Winston.

Vojtěch Kumbár, J. V. (2014). EXCESSIVE ADDITIVE EFFECT ON ENGINE OIL VISCOSITY. ACTA UNIVERSITATIS AGRICULTURAE ET SILVICULTURAE MENDELIANAE BRUNENSIS, vol:62 pp:1015-1021. 